\title{
Three Dimensional Morphometry of Distal Femur to Design Knee Prosthesis for Indonesian Population
}

\author{
Morfometría Tridimensional del Fémur Distal para Diseñar \\ Prótesis de Rodilla para la Población Indonesia
}

\author{
Rahadyan Magetsari"; Suyitno**; Rini Dharmastiti"*; Urip A. Salim**; \\ Luthfi Hidayat"; Twody Yudiman*; Zikrina A. Lanodiyu* \& Punto Dewo*
}

MAGETSARI, R.; SUYITNO; DHARMASTITI, R.; SALIM, U.A.; HIDAYAT, L.; YUDIMAN, T.; LANODIYU, Z.A. \& DEWO, P. Three dimensional morphometry of distal femur to design knee prosthesis for Indonesian population. Int. J. Morphol., 33(4):1255$1260,2015$.

SUMMARY: The objective of this study was to design custom-made prosthesis in a certain population, the morphometry needs to be measured. The results of this study were expected to provide basic data to design the ideal size of the total knee arthoplasty prosthesis for Indonesian population. This was an anthropometric study conducted on 100 healthy Indonesian population based on Computer Tomographic (CT) imaging on the distal femur resected surface. The parameters being used were Femoral Medio Lateral (fML) length, Femoral Antero Posterior (fAP) length, Femoral Medial Antero Posterior (fMAP) length, Femoral Lateral Antero Poste-

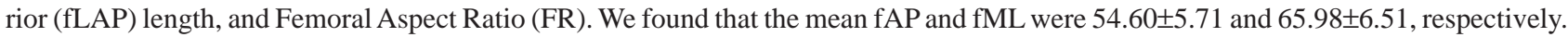
The morphometry of the distal femur were significantly different between male and female (male have larger build), however one of parameters showed different result: fLAP. This study showed that Indonesian people have smaller build compared with their Western counterpart. The proposed dimensions can be used as the basic data to design the ideal size of the custom-made knee arthoplasty prosthesis for Indonesian population.

KEY WORDS: Distal femur morphometry; Computed tomography; Knee prosthesis; Indonesian population.

\section{INTRODUCTION}

The need of Total Knee Replacement (TKR) has been increasing since the incidence of osteoarthritis is forecast to increase with the rapidly ageing population. Knee osteoarthritis occur around forty percent of people over 70 years of age, with $25 \%$ of this group experiencing a major disturbance of daily activities (World Health Organization, 1997). Osteoarthritis on the knee may lead to persistent pain, stiffness, weakness, joint instability, and reduce in range of motion (Kotti et al., 2014). Joint replacements are considered beneficial for removing pain and improve subjects quality of live in severe cases.

Appropriate prosthetic selection, accurate sizing, and proper placement of the components contribute to the success of total knee arthroplasty. It is a precision surgery where equal flexion-extension spacing should be achieved to allow joint stability throughout the range of motion (Laskin, 1981; Dorr \& Boiardo, 1986). A ready-made commercial implant may not conform to a patient anatomy resulting in the severe balancing problem and a short-term durability. Designing custom-made knee joint prosthesis in a certain population was done by reconstructing the knee in 3 dimensions, measuring the knee morphometry (articular surfaces, tibial, and femoral components), drafting the initial implant, evaluating the implant with finite element method (FEM) by virtual surgery, and determining final implant model (Jun, 2011). The benefits of well suited knee joint prosthesis are to improve knee functional outcome, achieve simplicity in the form of geometry, and comply the biocompatibility aspect (Anasane et al., 2007). Total knee prostheses that is made based on the accurately morphologic data of knee and gender morphologic differences may expected to give better results (Cheng et al., 2009).

Most of the commercially available total knee arthoplasty prosthesis used in Indonesia are made based on

\footnotetext{
* Department of Orthopaedics and Traumatology, Sardjito General Hospital/ Faculty of Medicine, Universitas Gadjah Mada, Yogyakarta, Indonesia.

** Department of Mechanical and Industrial Engineering, Faculty of Engineering, Universitas Gadjah Mada, Yogyakarta, Indonesia.
} 
MAGETSARI, R.; SUYITNO; DHARMASTITI, R.; SALIM, U. A.; HIDAYAT, L.; YUDIMAN, T.; LANODIYU, Z. A. \& DEWO, P. Three dimensional morphometry of distal femur to design knee prosthesis for Indonesian population. Int. J. Morphol., 33(4):1255-1260, 2015.

Western population. However, prostheses designed for Cauacasian patients are usually not suitable for Asian population because Asian population generally has a smaller build and stature compared with western counterparts as shown in several studies (Cheng et al.; Ho et al., 2006; Kwak et al., 2007).

We performed an anthropometric analysis on distal femur obtained from normal Indonesian knees using three dimensional computer tomographic measurements. The results of this study were expected to provide basic data to design the ideal size of the total knee arthoplasty prosthesis for Indonesian mongoloid population.

\section{MATERIAL AND METHOD}

Subjects. This was a descriptive analytic study conducted on sex matched 100 healthy Indonesian mongoloid race subjects with Javanese ethnicity with the age range from 20 to 70 years old. The inclusion criteria of this study were subjects with normal alignment of the lower extremity, absence of neuromuscular deformity and abnormality, absence of signs and symptoms of the knee arthritis, and independent daily activities performed by the subjects. The researchers selected the subjects by random sampling from the population of Indonesian mongoloid race lived in Yogyakarta, Indonesia. Information regarding this study was delivered to those eligible subjects and consent was taken. This study was reviewed and approved by ethical committees from Faculty of Medicine, Universitas Gadjah Mada. Measurement of the distal femur morphometry parameters was using right knee of the subjects.

Computer tomographic (CT) technique. The distal femur morphology in this study was measured based on Computer Tomographic (CT) imaging using CT-Scan Phillips ingenuity core 128,128 slices $120 \mathrm{kvp}, 2,0 \mathrm{~mm}$. The subjects were asked to lie in supine position with their patella facing superiorly. The retrieved image was formed in the file shape of DICOM 3.0, then it was reconstructed into 3D image with Phillips Intelli space portal CT viewer version 4.0.0.1921 software that was integrated with the CT Scan. Those distal femur 3D model image was 360 degree rotatable, could be cut and measured into desired area.

Distal femoral cuts and morphometry measurements. The parameters of distal femur being used in this study were Femoral Medio Lateral (fML) length, Femoral Antero Posterior (fAP) length, Femoral Medial Antero Posterior (fMAP) length, Femoral Lateral Antero Posterior (fLAP) length, and Femoral Aspect Ratio (FR). The center point of the intramedullary canal at the distal third of the femur was marked. Femoral anatomic axis was drawn as a line connecting that point to the center point of transepicondyle introcession. Then the cutting was made $9 \mathrm{~mm}$ above the lowest point of the medial condyle of distal femur with $6^{\circ}$ valgus from the femoral anatomic axis. The femoral mediolateral (ML) axis was measured between the most medial and the most lateral prominences of the respective epicondyles or the transepicondylar axis, while the femoral anteroposterior (AP) axis was measured perpendicularly to the ML axis. Therefore, the fML was taken as the width of ML axis in the resected surface of the distal femur, while the fAP was defined as the total width of the lateral condyle in the AP axis. The fMAP and fLAP measurements were carried out as the widest part of the medial and lateral condyles in the AP axis. Then, the FR could be calculated as the $\mathrm{fML}$ dimension divided by the fAP dimension $\mathrm{x}$ 100 (fML/fAP \%) (Cheng et al, 2009).

Independent $\mathrm{T}$ test was used to analyze the distal femur morphology between male compared with female subjects and Pearson correlation test was used to know the correlation between variables. Proposed dimension of the distal femur components was calculated based on 25 , 50 , and 75 percentile of the data. Values for $\mathrm{p}<0.05$ were regarded as stastically significant.

\section{RESULTS}

We studied the morphology of distal femur of 100 normal knee with equal number of male and female. The mean of age was 49.9 years and it was not significantly different between male and female subjects with $\mathrm{p}$ value 0.767 (Table I). All the subjects in this study did not have severe changes in the knee.

This study showed that morphometry of the distal femur were significantly different between male and female (male subjects had larger builds), however one of parameters showed different result: fLAP was not significantly different ( $\mathrm{p}$ value 0.054) (Table II). Meanwhile, the correlation between variables was shown in Table III. fML and fAP has shown to have moderate correlation in all subject and male group $(r=0.503$ and $r=$ $0.395)$, however it was only mild correlation in female group ( $\mathrm{r}=0.914$ ) (Fig. 1). The FR and fAP has shown to have strong correlation in male and female groups with $\mathrm{r}=$ 0.750 and $r=0.757$ (Fig. 2). The proposed dimension of the distal femur components for knee prostheses were seen in Table IV. 
Table I. Morphology of distal femur in all sex subjects.

\begin{tabular}{lcccccc}
\hline & $\mathbf{n}$ & Minimum & Maximum & Median & Mean \pm SD & $\begin{array}{c}\text { 95\% CI for mean } \\
\text { (lower }- \text { upper) }\end{array}$ \\
\hline Age & 100 & 20 & 73 & 55 & $49.95 \pm 15.71$ & $46.83-53.07$ \\
fML & 100 & 52.90 & 84.10 & 65.45 & $65.98 \pm 6.51$ & $64.68-67.27$ \\
fAP & 100 & 41.30 & 79.10 & 54.60 & $54.60 \pm 5.71$ & $53.46-55.73$ \\
fMAP & 100 & 28.40 & 58.00 & 41.45 & $42.56 \pm 5.58$ & $41.45-43.67$ \\
fLAP & 100 & 28.30 & 60.60 & 41.95 & $42.13 \pm 6.09$ & $40.92-43.34$ \\
FR & 100 & 91.9090 & 160.7456 & 120.61 & $121.55 \pm 12.54$ & $119.06-124.03$ \\
\hline
\end{tabular}

Table II. Descriptive statistic and comparison between male and female subjects (mm).

\begin{tabular}{lcccccccc}
\hline & Sex & $\mathbf{n}$ & Mean \pm SD & $\begin{array}{c}\text { Std. Error } \\
\text { Mean }\end{array}$ & $\begin{array}{c}\text { Mean } \\
\text { Difference }\end{array}$ & $\begin{array}{c}\text { 95\% CI of the } \\
\text { Difference }\end{array}$ & $\begin{array}{c}\text { Std. Error } \\
\text { Difference }\end{array}$ & Sig. (2-tailed) \\
\hline \multirow{2}{*}{ Age } & Male & 50 & $49.48 \pm 16.15$ & 2.285 & -0.940 & $-7.20-5.32$ & 3.158 & 0.767 \\
& Female & 50 & $50.42 \pm 15.41$ & 2.180 & & & & \\
fML & Male & 50 & $70.56 \pm 5.17$ & 0.73202 & & & & \\
& Female & 50 & $61.40 \pm 4.01$ & 0.56726 & 9.16 & $7.32-11.00$ & 0.92609 & 0.000 \\
fAP & Male & 50 & $56.96 \pm 6.09$ & 0.86182 & & & & 0.000 \\
& Female & 50 & $52.24 \pm 4.18$ & 0.59140 & 4.72 & $2.64-6.79$ & 1.04522 & \\
fMAP & Male & 50 & $44.27 \pm 4.91$ & 0.69569 & & & & \\
& Female & 50 & $40.85 \pm 5.73$ & 0.81156 & 3.41 & $1.29-5.53$ & 1.06893 & 0.002 \\
fLAP & Male & 50 & $43.30 \pm 6.75$ & 0.95488 & & & & \\
& Female & 50 & $40.95 \pm 5.17$ & 0.73150 & 2.34 & $-0.03-4.73$ & 1.20287 & 0.054 \\
FR & Male & 50 & $124.88 \pm 12.80$ & 1.8102279 & & & & \\
& Female & 50 & $118.21 \pm 11.45$ & 1.6199155 & 6.67 & $1.85-11.49$ & 2.4292079 & 0.007 \\
\hline
\end{tabular}

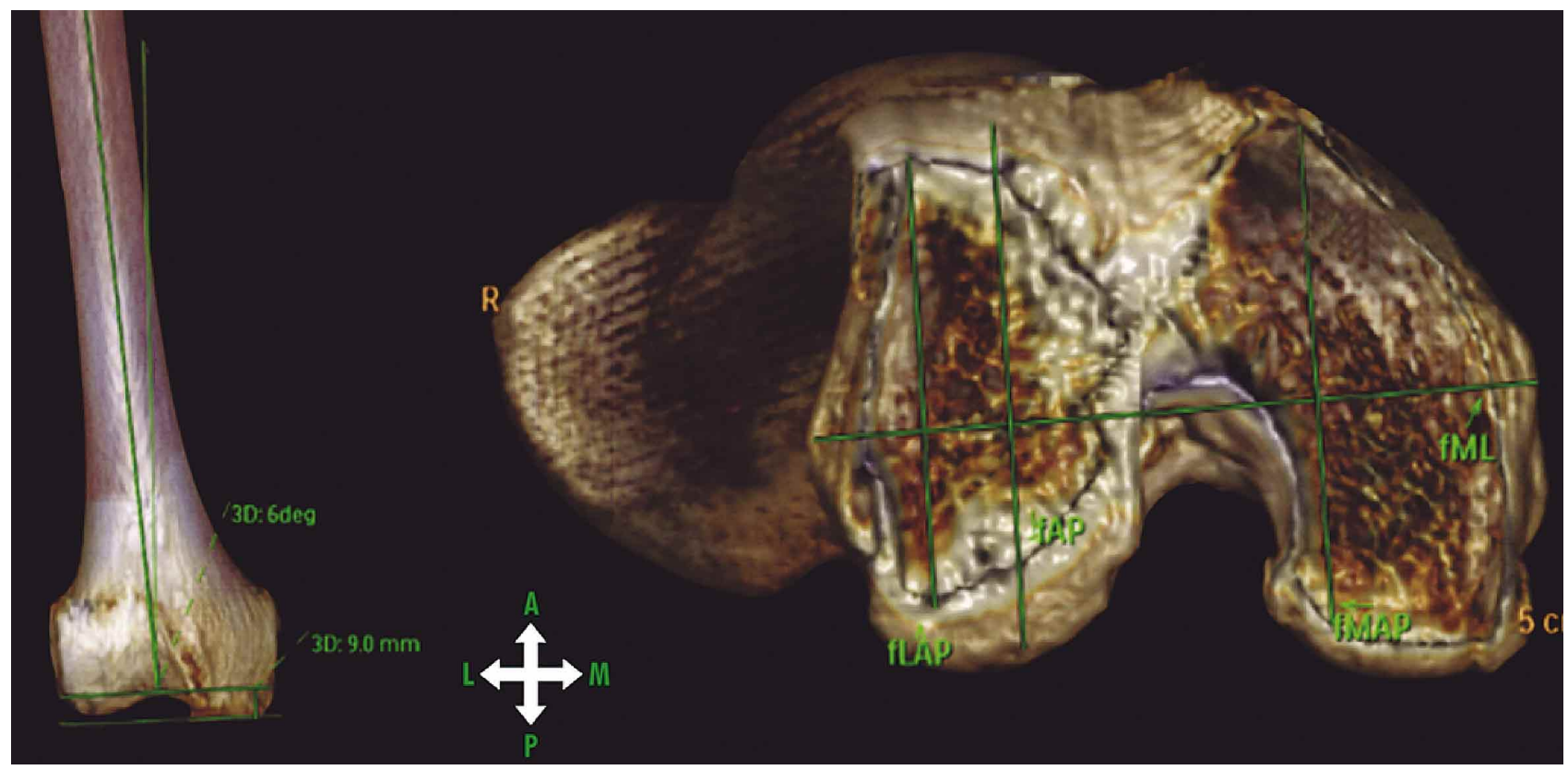

Fig. 1. Distal femoral cuts and morphometry measurements used in this study. 


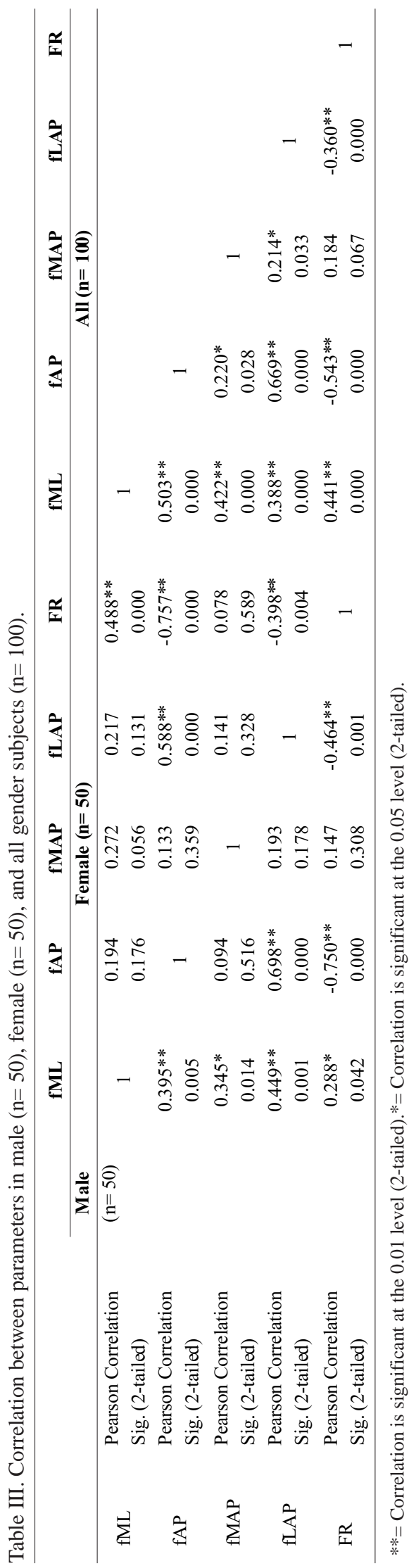

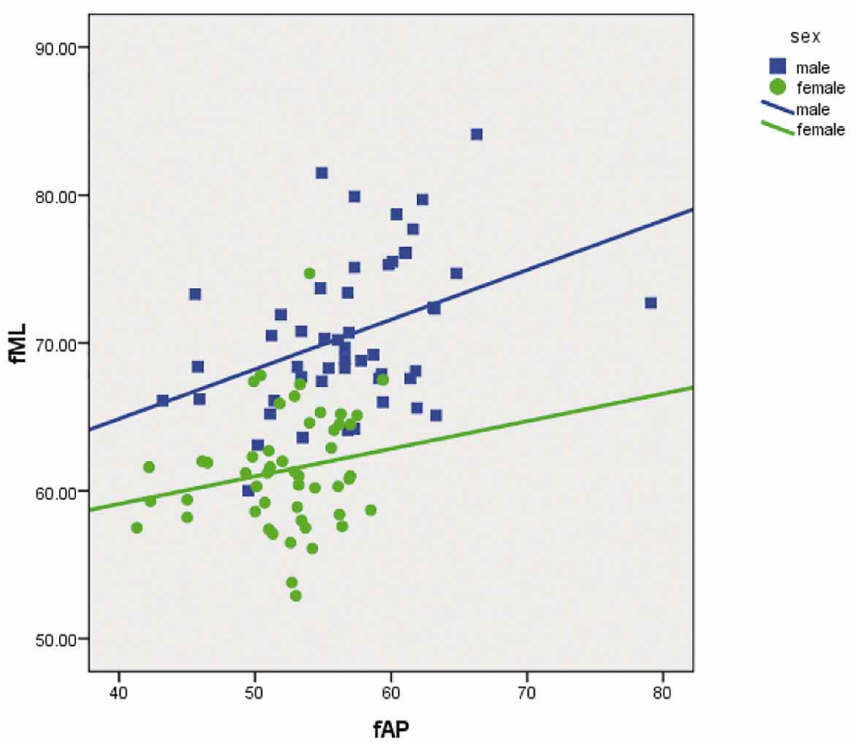

Fig. 2. The morphological relationship between fML and fAP in Indonesian mongoloid between male and female.

Table IV. Proposed dimension of the distal femur components in knee prostheses for Indonesian population $(\mathrm{mm})$ based on $25^{\text {th }}, 50^{\text {th }}$, and $75^{\text {th }}$ percentile.

\begin{tabular}{lcccc}
\hline Sex & Percentile & fML & fAP & FR \\
\hline Male & 25 & 67.10 & 53.40 & 115.14 \\
& 50 & 69.45 & 56.85 & 124.94 \\
Female & 75 & 73.95 & 61.02 & 129.43 \\
& 25 & 58.55 & 50.32 & 110.14 \\
& 50 & 61.10 & 52.95 & 115.84 \\
All & 75 & 64.50 & 55.65 & 125.65 \\
& 25 & 61.00 & 51.12 & 113.13 \\
& 50 & 65.45 & 54.60 & 120.60 \\
& 75 & 70.07 & 57.30 & 128.43
\end{tabular}

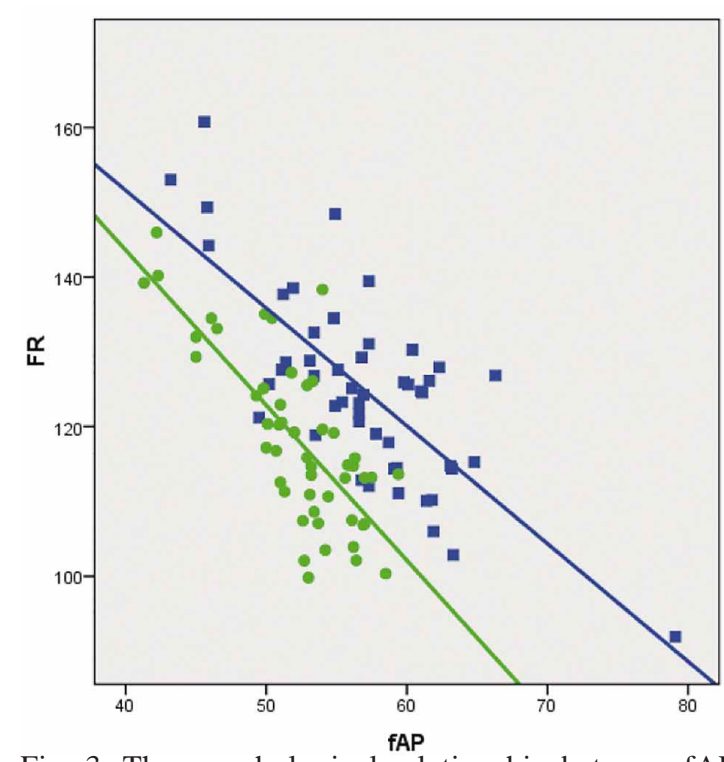

Fig. 3. The morphological relationship between fAP and FR in Indonesian mongoloid between male and female. 


\section{DISCUSSION}

Well-matched prosthesis to the resected surface of the knee is one of the important factor for long term success with lesser complication in total knee arthoplasty (Cheng et al., 1999). The actual measurenment can be carried out intraoperatively, however, a study conducted by Lee et al . (2006), showed that CT measurement and intraoperative measurement were in almost perfect agreement. Moreover, 3D CT image that was being used in this study can be rotated and three dimensional axis can be maintained, so that the actual size of the morphometry can be measured.

Anteroposterior and mediolateral dimension are major dimension in the femoral implant. To develop well suited femoral implant, the AP length is used in correlation with gait motion and accurate ligamentous balancing in flexion and extension (Dorr \& Boiardo). Several studies based on Caucasian population as the subjects of the study showed that the mean of anterior posterior and mediolateral dimension was larger compared with distal femoral morphometry in Asian population (Mensch \& Amstutz, 1975; Berger et al., 1993; Griffin et al., 2000). It was in accordance to this study where this study showed that the mean of fML and fAP was $65.98 \pm 6.51$ and $54.60 \pm 5.71$ in our study population and smaller compared with Caucassian population.

Several studies have been conducted on distal femur morphometry measurement in Asian population. Indonesian mongoloid have smaller builds in terms of fML and fAP compared with Indian, Japanese, Korean and Chinese population (Cheng et al., 2009; Ho et al.; Lee et al.; Chow, 1996; Urabe et al., 2003). They were also smaller in terms of other variables such as fMAP and fLAP compared with Chinese and Indian population (Cheng et al., 2009; Suryanarayan et al., 2014). Among South East Asian mongoloid population, Indonesian has similar morphometry compared with Thai population. Indonesian and Thai had similar size and large femur aspect ratio (Chaichankul et al., 2011). Large femur ratio reflects the shape of the distal femur, and it means that the shape of distal femur was mediolaterally oval. The femur aspect ratio of Indonesian was $121.5 \pm 12.5$ and based on a study conducted by Chaicankul et al., Thai people have femur aspect ratio of $141 \pm 12$. When they were compared with Chinese population, they had larger femur aspect ratio (FB Cheng). However, a study conducted in Malaysia based on Malay population showed slightly larger distal femoral size than that in this study, even though it was still smaller compared with Western counterpart (Hussain et al., 2013).
This study was expected to be useful for further study in developing knee implant designs for Indonesian mongoloid population. Therefore, well-matched prosthesis can be made and successful surgery can be achieved. Further studies based on larger sample of Indonesian mongoloid race are recommended.

\section{CONCLUSION}

The anthropometric data on distal femur morphometry of Indonesian population showed that Indonesian has a smaller build compared with western counterpart. This study may provide guidance for designing well matched knee prosthesis for Indonesian population.

\section{ACKNOWLEDGEMENTS}

We acknowledge the financial support of the Pusnas DIKTI. We thank Gadjah Mada Hospital for allowing us to use the CT work station.

MAGETSARI, R.; SUYITNO; DHARMASTITI, R.; SALIM, U. A.; HIDAYAT, L.; YUDIMAN, T.; LANODIYU, Z. A. \& DEWO, P. Morfometría tridimensional del fémur distal para diseñar prótesis de rodilla para la población indonesia. Int. J. Morphol., 33(4):1255-1260, 2015.

RESUMEN: El objetivo fue diseñar una prótesis a medida para una determinada población, por tanto la morfometría debía ser medida para proporcionar datos básicos para diseñar el tamaño ideal de una prótesis total para la artroplastia de rodilla en población de Indonesia. Se realizó un estudio antropométrico sobre 100 sujetos sanos indonesios, basados en tomografías computadorizadas (TC) de la superficie resecada del fémur distal. Los parámetros que se midieron fueron longitud femoral mediolateral (FML), longitud femoral anteroposterior (FAP), longitud femoral medial anteroposterior (FMAP), longitud femoral lateral anteroposterior (FLAP), y razón de aspecto femoral (FR).

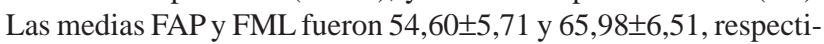
vamente. La morfometría del fémur distal fue significativamente diferente entre hombres y mujeres (mayor tamaño en hombres), sin embargo uno de los parámetros mostró resultados diferentes, la FLAP. Las personas indonesias son de menor tamaño en comparación con su contraparte occidental. Las dimensiones propuestas se pueden utilizar como los datos básicos para diseñar el tamaño ideal para una prótesis de rodilla a medida para la población de Indonesia.

PALABRAS CLAVE: Morfometría; Femur distal; Tomografía computadorizada; Prótesis de rodilla; Población indonesia. 
MAGETSARI, R.; SUYITNO; DHARMASTITI, R.; SALIM, U. A.; HIDAYAT, L.; YUDIMAN, T.; LANODIYU, Z. A. \& DEWO, P. Three dimensional morphometry of distal femur to design knee prosthesis for Indonesian population. Int. J. Morphol., 33(4):1255-1260, 2015.

\section{REFERENCES}

Anasane, S.; Pandey, A.; Rathi, K. K.; Panda, N. \& Rafi, B. Total knee prosthesis: design, manufacture, and testing. Indian J. Surg., 4:354-60, 2007.

Berger, R. A.; Rubash, H. E.; Seel, M. J.; Thompson, W. H. \& Crossett, L. S. Determining the rotational alignment of the femoral component in total knee arthroplasty using the epicondylar axis. Clin. Orthop. Relat. Res., (286):40-7, 1993.

Chaichankul, C.; Tanavalee, A. \& Itiravivong, P. Anthropometric measurements of knee joints in Thai population: correlation to the sizing of current knee prostheses. Knee, 18(1):5-10, 2011.

Cheng, C. K.; Lung, C. Y.; Lee, Y. M. \& Huang, C. H. A new approach of designing the tibial baseplate of total knee prostheses. Clin. Biomech. (Bristol, Avon), 14(2):112-7, 1999.

Cheng, F. B.; Ji, X. F.; Lai, Y.; Feng, J. C.; Zheng, W. X.; Sun, Y. F.; Fu, Y. W. \& Li, Y. Q. Three dimensional morphometry of the knee to design the total knee arthroplasty for Chinese population. Knee, 16(5):341-7, 2009.

Chow, S. L. Design and analysis of a total knee prosthesis. MEng thesis. Nanyang, Nanyang Technological University, 1996.

Dorr, L. D. \& Boiardo, R. A. Technical considerations in total knee arthroplasty. Clin. Orthop. Relat. Res., (205):5-11, 1986.

Griffin, F. M.; Math, K.; Scuderi, G. R.; Insall, J. N. \& Poilvache, P. L. Anatomy of the epicondyles of the distal femur: MRI analysis of normal knees. J. Arthroplasty, 15(3):354-9, 2000.

Ho, W. P.; Cheng, C. K. \& Liau, J. J. Morphometrical measurements of resected surface of femurs in Chinese knees: correlation to the sizing of current femoral implants. Knee, 13(1):12-4, 2006.

Hussain, F.; Abdul Kadir, M. R.; Zulkifly, A. H.; Sa'at, A.; Aziz, A. A.; Hossain, G.; Kamarul, T. \& Syahrom, A. Anthropometric measurements of the human distal femur: a study of the adult Malay population. Biomed. Res. Int., 2013:175056, 2013.

Jun, Y. Morphological analysis of the human knee joint for creating custom-made implant models. Int. J. Adv. Manuf. Technol., 52(9):841-53, 2011.

Kotti, M.; Duffell, L. D.; Faisal, A. A. \& McGregor, A. H. The complexity of human walking: a knee osteoarthritis study. PloS One, 9(9):e107325, 2014.

Kwak, D. S.; Surendran, S.; Pengatteeri, Y. H.; Park, S. E.; Choi, K. N.; Gopinathan, P.; Han, S. H. \& Han, C. W. Morphometry of the proximal tibia to design the tibial component of total knee arthroplasty for the Korean population. Knee, 14(4):29530, 2007.
Laskin, R. S. Total condylar knee replacement in rheumatoid arthritis. A review of one hundred and seventeen knees. J. Bone Joint Surg. Am., 63(1):29-35, 1981.

Lee, I. S.; Choi, J. A.; Kim, T. K.; Han, I.; Lee, J. W. \& Kang, H. S. Reliability analysis of 16-MDCT in preoperative evaluation of total knee arthroplasty and comparison with intraoperative measurements. AJR Am. J. Roentgenol., 186(6):1778-82, 2006.

Mensch, J. S. \& Amstutz, H. C. Knee morphology as a guide to knee replacement. Clin. Orthop. Relat. Res., (112):231-41, 1975.

Suryanarayan, P.; Navneet, J. \& Ashok P. CT evaluation and study: anthropometric measurement of knee joint in asian population. Int. J. Sci. Res. Publ., 4(12):1-12, 2014.

Urabe, K.; Miura, H.; Kuwano, T.; Matsuda, S.; Nagamine, R.; Sakai, S.; Masuda, K. \& Iwamoto, Y. Comparison between the shape of resected femoral sections and femoral prostheses used in total knee arthroplasty in Japanese patients: simulation using three-dimensional computed tomography. J. Knee Surg., 16(1):27-33, 2003.

World Health Organization (WHO). World Health Report, 50 facts. Geneva, WHO, 1997. Available from: http://www.who.int/whr/ 1997/media_centre/50facts/en/

Correspondence to:

Zikrina A. Lanodiyu, MD.

Department of Orthopaedics and Traumatology

Sardjito General Hospital

Faculty of Medicine Universitas Gadjah Mada

Jalan Kesehatan no. 1

Yogyakarta 56281

INDONESIA

Email: zikrina.lanodiyu158@gmail.com

Received: 29-04-2015

Accepted: 20-08-2015 